\title{
Microbial Community Composition of Two Environmentally Conserved Estuaries in the Midorikawa River and Shirakawa River
}

\author{
Tran Thanh Liem ${ }^{1 *}$, Mitsuaki Nakano ${ }^{1}$, Hiroto Ohta ${ }^{1}$, Takuro Niidome $^{1}$, Tatsuya Masuda ${ }^{2}$, \\ Kiyoshi Takikawa ${ }^{3}$, Shigeru Morimura ${ }^{1}$ \\ ${ }^{1}$ Graduate School of Science and Technology, Kumamoto University, Kumamoto City, Japan \\ ${ }^{2}$ Priority Organization for Innovation and Excellence, Kumamoto University, Kumamoto City, Japan \\ ${ }^{3}$ Center for Marine Environment Studies, Kumamoto University, Kumamoto City, Japan
}

\begin{abstract}
To provide a general overview of the microbial communities in environmentally conserved estuaries, the top $5 \mathrm{~cm}$ of sediment was sampled from the sandy estuary of the Shirakawa River and from the muddy estuary of the Midorikawa River. Higher amounts of organic matter were detected in the Midorikawa estuary sample than in the Shirakawa estuary sample. Measurement of redox potential revealed that the Shirakawa estuary was aerobic and the Midorikawa estuary was much less aerobic. Clone analysis was performed by targeting partial 16S rRNA gene sequences and using extracted DNA from the samples as a template. Various bacteria were detected, among which Gammaproteobacteria was dominant at both estuaries. Unclassified clones were detected in the Gammaproteobacteria group, mainly among samples from the Midorikawa estuary. Other detected bacterial groups were Alphaproteobacteria, Deltaproteobacteria, Chloroflexi, Actinobacteria, and Bacteroidetes. All the Deltaproteobacteria clones were anaerobic sulfate-reducing bacteria. Those aerobic and anaerobic bacteria coexisted in the top $5 \mathrm{~cm}$ of the estuary sediments indicating the surface layer have active sulfur and carbon cycle. Abundance of aerobic Gammaproteobacteria may be an indicator for conserved estuaries.
\end{abstract}

Keywords: conserved environment, clone analysis, estuary, microbial community, 16S rRNA gene.

\section{INTRODUCTION}

In recent years, environmental conditions in the Ariake Sea, which contains roughly $40 \%$ of Japan's tidal flats, have worsened, leading to problems such as red tides and reduced fishery output. Tidal flats are extremely valuable ecosystems, serving as a habitat and playing diverse roles in processes such as water purification and biological production. Microorganisms are a key part of the tidal flat system. In sandy tidal flats aerobic bacteria utilize and degrade organic compounds; however, in muddy tidal flats only the surface, not lower layers of sediment, is exposed to oxygen. Under these anaerobic conditions, hydrogen sulfide is easily generated by sulfate-reducing bacteria (SRB), producing a dark sediment color [1]. Although muddy tidal flats that have been environmentally conserved have nested holes populated by aerobic macrobenthic organisms, demonstrating that a muddy ecosystem itself is

\footnotetext{
* Correspondence author:

Tran Thanh Liem

Email : liemmt2003@yahoo.com

Address : Graduate School of Science and Technology, Kumamoto University, 2-39-1 Kurokami Chuo-ku, Kumamoto City, Kumamoto 860-8555, Japan
}

not problematic, an imbalance in the metabolisms of anaerobic microorganisms will lead to harmful accumulation of hydrogen sulfide.

Changes have been reported in the microbial community of marine sediment following environmental contamination with pollutants such as oil [2-4] or heavy metals [5,6], but only a few studies have observed microbial communities under environmentally conserved conditions $[7,8]$. In the present study, two estuaries connecting to the Ariake Sea were sampled: the Shirakawa River estuary with sandy sediment and the Midorikawa River estuary with muddy sediment. Sites were chosen due to their high numbers of nested holes, the presence of salt-tolerant plants growing at higher water marks, and their conserved environmental conditions. Microbial communities were analyzed by targeting partial 16S rRNA gene sequences to provide a general overview of the microbial communities in environmentally conserved tidal flat sediment. 


\section{MATERIALS AND METHODS}

\section{Sampling}

Estuary sediment were sampled using sterilized spatula from the left bank of the Shirakawa River (N32 $46^{\prime} 38.9^{\prime \prime}, \mathrm{E} 130^{\circ} 36^{\prime} 33.6^{\prime \prime}$ ) and the right bank of the Midorikawa River (N32 $42^{\prime} 48.3^{\prime \prime}$, E130 $37^{\prime} 21.2^{\prime \prime}$ ) on May 22, 2008 and January 27, 2009. Both rivers are located in coastal areas bordering the Ariake Sea in Kumamoto Prefecture, Japan (Fig. 1). All sediment samples were collected to a depth of $5 \mathrm{~cm}$ at low tide. At each sampling site, samples were collected at both the high tide position and the low tide position, as shown in Fig. 2. All samples were kept at $-20^{\circ} \mathrm{C}$ until used for analysis.

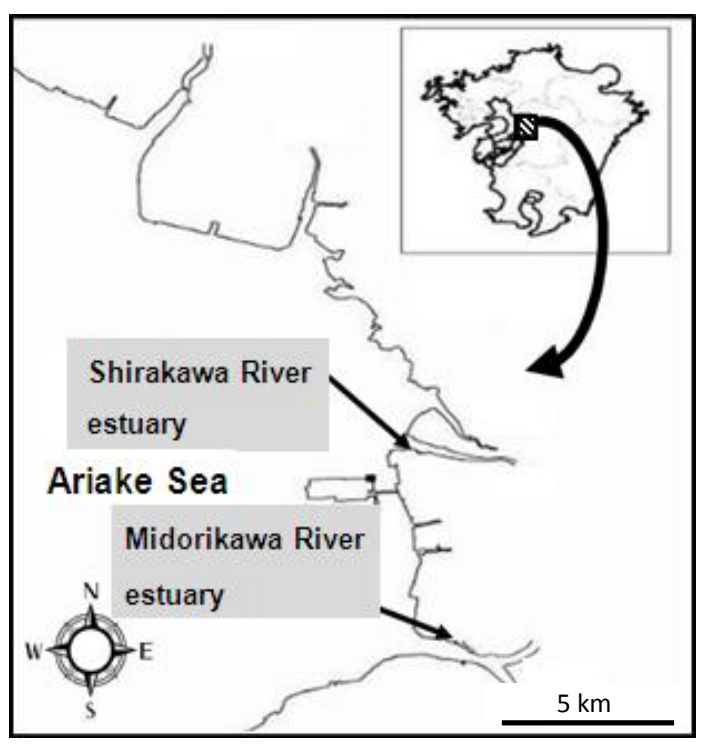

Figure 1. Sampling site Location of sampling sites in the Shirakawa and Midorikawa River estuaries connecting to the Ariake Sea

\section{DNA Extraction}

Frozen samples were thawed on ice and centrifuged at $10,000 \times g$ at $4^{\circ} \mathrm{C}$ for $15 \mathrm{~min}$. The precipitate was washed in sterilized phosphate buffered saline solution and was centrifuged again at the same settings. The supernatant was removed. The precipitate was mixed well and 0.5 $\mathrm{g}$ of the sample was used to extract DNA with the Fast DNA SPIN Kit for Soil (MP Biomedicals, Solon, $\mathrm{OH}$ ) according to the manufacturer's protocol. DNA concentrations were measured at wavelength of 260nm (Beckman DU 530 UV-VIS Spectrophotometer).

\section{Determination of Microbial Community}

The extracted DNA was used as a template for polymerase chain reaction (PCR) targeting partial 16S rRNA gene sequences. The primer set 27F (5'-AGA GTT TGA TCC TGG CTC AG-3') and 518R (5'-GTA TTA CCG CGG CTG CTG G-3') and AmpliTaq Gold (Applied Biosystems, Carlsbad, CA) were used. After preheating at $95^{\circ} \mathrm{C}$ for 5 min, 25 cycles were performed of heating at $95^{\circ} \mathrm{C}$ for $1 \mathrm{~min}$, annealing at $50^{\circ} \mathrm{C}$ for $1 \mathrm{~min}$, and extension at $72^{\circ} \mathrm{C}$ for $2 \mathrm{~min}$. PCR products were purified by an Ultra Clean PCR Clean-up Kit (MOBIO, Carlsbad, CA) according to the manufacturer's protocol. Purified PCR products were ligated with pT7Blue vector (Novagen, Darmstadt, Germany), using a Ligation Mix Kit (Takara, Kyoto, Japan) according to the manufacturer's protocol. Then, $100 \mu \mathrm{L}$ of competent Escherichia coli $\mathrm{DH} 5 \alpha$ cells (Takara, Kyoto, Japan) was transformed with $10 \mu \mathrm{L}$ of ligation mixture as mentioned in manufacturer's protocol. After colonies formed on an LBampicillin plate containing X-gal, white colonies were selected and plasmids were extracted using the Wizard SV Minipreps DNA Purification System (Promega, Madison, WI). Extracted plasmids were digested by EcoRI and Pstl (Takara, Kyoto, Japan) to determine the size of the inserted DNA. Sequence analysis of the inserted DNA was completed by Takara Co., Ltd. by premixed sequencing with M13 (-47) primer (5'-CGC CAG GGT TTT CCC AGT CAC GAC-3').

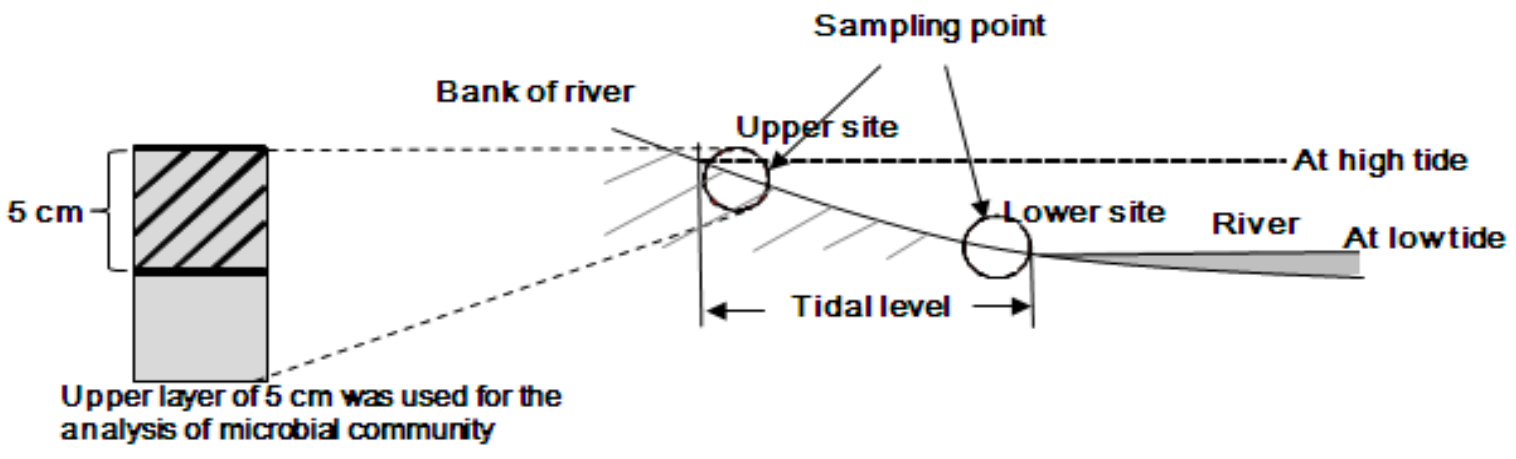

Figure 2. Location of sampling points at each estuary 
Data from the analysis were compared to the NCBI database by a BLAST search to identify obtained clones [9]. 16S rRNA nucleic acid sequences were aligned using ClustalX 1.8 software [10]. Phylogenetic trees were constructed using MEGA 4 software [11]. In which, nucleotide sequences were used to build phylogenetic trees using Distance-based method that measures the pairwise distance between genes. More detail, we chose Neighbor-Joining method in Bootstrap test of Phylogeny option from Phylogeny menu, selected Pairwise Deletion for Gaps/Missing Data to retain all sites containing alignment gaps and missing information before start computing.

\section{Environmental Parameters Analysis}

Hydrogen ion and $\mathrm{NaCl}$ concentration were measured using a handheld $\mathrm{pH}$ meter and surface salinity meter (SSM14-P and WM-22EP; TOADKK, Tokyo, Japan). Redox potential (ORP) was measured using a portable ORP meter (RM20P; TOADKK) and distribution of particle size was analyzed using a laser diffraction particle size analyzer (LA-920; HORIBA, Kyoto, Japan). Organic matter was determined by measurement of residual weight after heating according to the Japanese Standard Method, JIS-K0102 [12]. The partial 16S rRNA gene sequences obtained in this work have been deposited in the DNA Data Bank of Japan (DDBJ) under accession numbers AB853487-AB853725.

\section{RESULTS AND DISCUSSION}

Environmental Conditions at Sampling Sites

Environmental conditions at the Midorikawa and Shirakawa estuaries are summarized in Table 1. Generally, pH was in the range 7.5 and 8.0. Because river water and seawater were mixed at the sites, $\mathrm{NaCl}$ concentration was lower than $3.5 \%$, the average concentration of seawater, due to dilution by fresh water from the rivers. ORP values were positive for the Shirakawa estuary and negative for the Midorikawa estuary, suggesting that their conditions were aerobic and slightly anaerobic, respectively. Organic content in the sediment at the Midorikawa estuary was higher than that at the Shirakawa estuary. Median particle size data and mud content analysis suggested that the Shirakawa estuary was sandy and the Midorikawa estuary was muddy. Taken together, these results confirmed that ORP was low and organic content was high under conditions of low median particle size and high mud content.

Table 1. Environmental Conditions at Shirakawa and Midorikawa River Estuary

\begin{tabular}{|c|c|c|c|c|c|c|c|c|c|}
\hline Season & $\begin{array}{c}\text { Location of } \\
\text { estuaries }\end{array}$ & $\begin{array}{l}\text { Tide } \\
\text { level }\end{array}$ & $\begin{array}{l}\text { Altitude } \\
\text { T.P. }(\mathrm{m})\end{array}$ & $\mathrm{pH}$ & $\begin{array}{c}\mathrm{NaCl} \\
(\%)\end{array}$ & $\begin{array}{l}\text { ORP } \\
(\mathrm{mV})\end{array}$ & $\begin{array}{c}\text { Organic matter } \\
\text { ng/g-dry sediment) }\end{array}$ & $\begin{array}{l}\text { Median particle } \\
\text { size }(\mu \mathrm{m})\end{array}$ & $\begin{array}{c}\text { Mud } \\
\text { content } \\
\text { (\%) }\end{array}$ \\
\hline \multirow[t]{4}{*}{ May } & Shirakawa & High & +1.494 & N.M. & N.M. & 210 & 6.3 & 143.4 & 31.8 \\
\hline & & Low & -0.476 & 7.78 & 1.97 & 180 & 23.7 & 99.4 & 47.6 \\
\hline & Midorikawa & High & +0.553 & 7.68 & 0.76 & -72 & 69.6 & 20.3 & 85.1 \\
\hline & & Low & -0.833 & 8.60 & 1.34 & -40 & 98.1 & 11.6 & 98.9 \\
\hline \multirow[t]{4}{*}{ Jan } & Shirakawa & High & N.M. & N.M. & N.M. & 231 & 12.4 & 76.1 & 49.7 \\
\hline & & Low & N.M. & 7.55 & 0.60 & 227 & 14.7 & 40.9 & 59.4 \\
\hline & Midorikawa & High & N.M. & 7.81 & 0.30 & -113 & 47.2 & 42.9 & 67.8 \\
\hline & & Low & N.M. & 7.54 & 0.33 & -21 & 76.5 & 17.9 & 86.0 \\
\hline
\end{tabular}

T.P.: Tokyo peil, N.M: Not measured

\section{Homology analysis among bacterial DNA sequences}

Partial 16S sequence data of the obtained clones analyzed by BLAST and their close phylum or class are summarized in Table 2. Many groups of bacteria were observed in the environmentally conserved Midorikawa and Shirakawa estuaries. In general, the dominant group was Gammaproteobacteria, comprising $22.6 \%$ of the total clones, and the second most dominant group was Alphaproteobacteria, comprising 15.9\%. Chloroflexi, Deltaproteobacteria, Actinobacteria, and Bacteroidetes were also common. The microbial community composition among different sampling sites, seasons, and tidal positions are compared in Fig. 3. High ratios of Deltaproteobacteria and Gammaproteobacteria were detected in Midorikawa estuary compared to Shirakawa estuary, which seemed related to the slightly more anaerobic conditions with higher amounts of organic matter. However, Gammaproteobacteria in the sediment of Shirakawa-river estuary in May was not so high, the low value of organic matter was observed at both hightide and lowtide positions, as well. 
The ratios of Alphaproteobacteria, Actinobacteria, and Bacteroidetes were higher in May than in January, possibly due to greater phototrophic production of organic compounds and subsequent aerobic degradation. In January, the ratio of Gammaproteobacteria at the low tide position was higher than that at the high tide position. While in May, the ratio of Gammaproteobacteria at the high tide position was higher than that at the low tide position. Although, the organic matter values at low tide positions were always higher than those at high tide positions.

Additionally, many Gammaproteobacteria clones were detected at the low tide position in the Midorikawa estuary, though they were uncultured bacteria.

Table 2. Closely related phylum or class for the detected clones as determined by homology analysis

\begin{tabular}{|c|c|c|c|c|c|c|c|c|}
\hline \multirow{3}{*}{$\begin{array}{l}\text { Sampled season } \\
\text { Place of estuary } \\
\text { Tide level position }\end{array}$} & \multicolumn{4}{|c|}{ May } & \multicolumn{4}{|c|}{ January } \\
\hline & \multicolumn{2}{|c|}{ Midorikawa } & \multicolumn{2}{|c|}{ Shirakawa } & \multicolumn{2}{|c|}{ Midorikawa } & \multicolumn{2}{|c|}{ Shirakawa } \\
\hline & High & Low & High & Low & High & Low & High & Low \\
\hline Deltaproteobacteria & 3 & 3 & 1 & 0 & 7 & 4 & 2 & 2 \\
\hline Firmicutes & 1 & 1 & 0 & 1 & 1 & 2 & 2 & 0 \\
\hline Chloroflexi & 1 & 3 & 5 & 3 & 6 & 1 & 2 & 4 \\
\hline Epsilonproteobacteria & 0 & 0 & 0 & 0 & 0 & 1 & 1 & 0 \\
\hline Alphaproteobacteria & 4 & 2 & 4 & 10 & 7 & 4 & 4 & 3 \\
\hline Betaproteobacteria & 0 & 0 & 0 & 0 & 0 & 1 & 1 & 1 \\
\hline Gammaproteobacteria & 10 & 6 & 4 & 1 & 4 & 18 & 2 & 9 \\
\hline Bacteroidetes & 2 & 6 & 5 & 2 & 1 & 1 & 2 & 1 \\
\hline Actinobacteria & 1 & 0 & 4 & 7 & 3 & 1 & 6 & 1 \\
\hline Acidobacteria & 1 & 2 & 1 & 0 & 6 & 2 & 4 & 4 \\
\hline Nitrospirae & 0 & 2 & 0 & 1 & 0 & 1 & 1 & 1 \\
\hline Planctomycetes & 1 & 0 & 2 & 1 & 2 & 0 & 0 & 2 \\
\hline Verrucomicrobia & 1 & 0 & 1 & 0 & 0 & 0 & 0 & 1 \\
\hline Cyanobacteria & 2 & 0 & 0 & 0 & 1 & 1 & 1 & 0 \\
\hline Thermotogae & 0 & 0 & 0 & 2 & 0 & 0 & 0 & 0 \\
\hline TOTAL & 27 & 25 & 27 & 28 & 38 & 37 & 28 & 29 \\
\hline
\end{tabular}
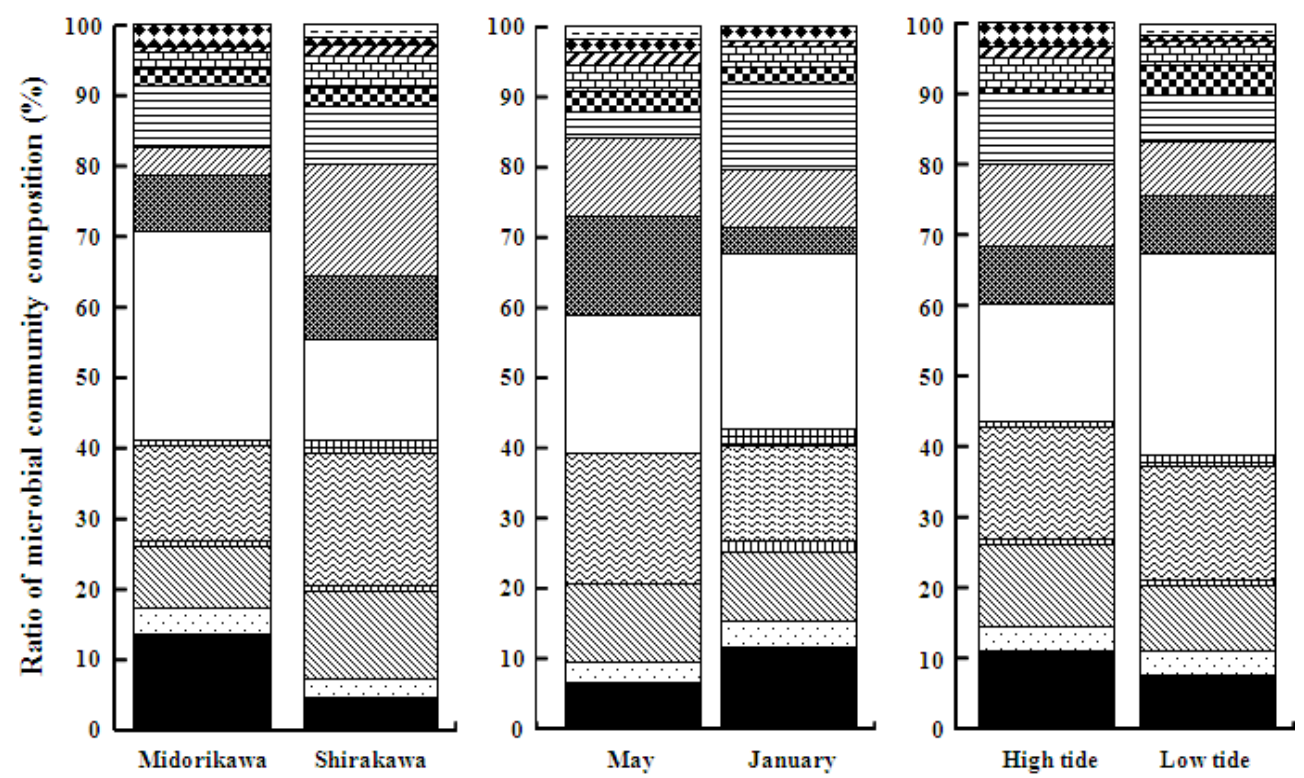

Figure 3. Comparison of microbial communities in different sediment compositions (muddy, Midorikawa; sandy, Shirakawa), at different seasons, and at different tidal positions. Patterns indicating clones: solid, Deltaproteobacteria; dotted, Firmicutes; right-down diagonals, Chloroflexi; vertical stripes, Epsilonproteobacteria; wavy lines, Alphaproteobacteria; hatching, Betaproteobacteria; open, Gammaproteobacteria; stitched, Bacteroidetes; left-down diagonals, Actinobacteria; horizontal stripes, Acidobacteria; checkmarks, Nitrospirae; rectangular blocks, Verrucomicrobia; diamonds, Cyanobacteria; dashes, Thermotogae. 


\section{Phylogenetic Tree Analysis of Bacterial}

\section{Communities}

Phylogenetic trees of dominant groups were constructed. The phylogenetic tree of the major group, Gammaproteobacteria, is shown in Fig. 4.

Many clones were most similar to uncultured bacteria. Among them, 22 clones in Gammaproteobacteria were close to Pseudomonas sp. (AB013829) isolated from deep-sea sediment [13], and were mainly observed in the Midorikawa estuary. Eight clones were similar to Kangiella aquimarina (NR025801), which was isolated from tidal flats of the Yellow Sea [14]. $K$. japonica was also isolated from coastal seawater and sediment samples in the Sea of Japan, Russia
[15]. Some Gammaproteobacteria clones were related to Nitrosococcus oceani (AB474000) [16] and others were close to Haliea sp. $[17,18]$. However, two clones detected in January were true sulfur-oxidizing bacteria (SOB) [19]. The phylogenetic tree for Deltaproteobacteria is shown in Fig. 5. All clones appeared to be SRB, and could be divided into 6 groups based on $16 \mathrm{~S}$ rRNA gene sequences [20]. Desulfotomaculum group was not detected and 5 other groups were detected. It showed same results of isolated SRB from estuarine sediment in Japan [21]. All 7 clones grouped in Desulfosarcina, Desulfococcus, and Desulfonema were detected in May as well as in January.

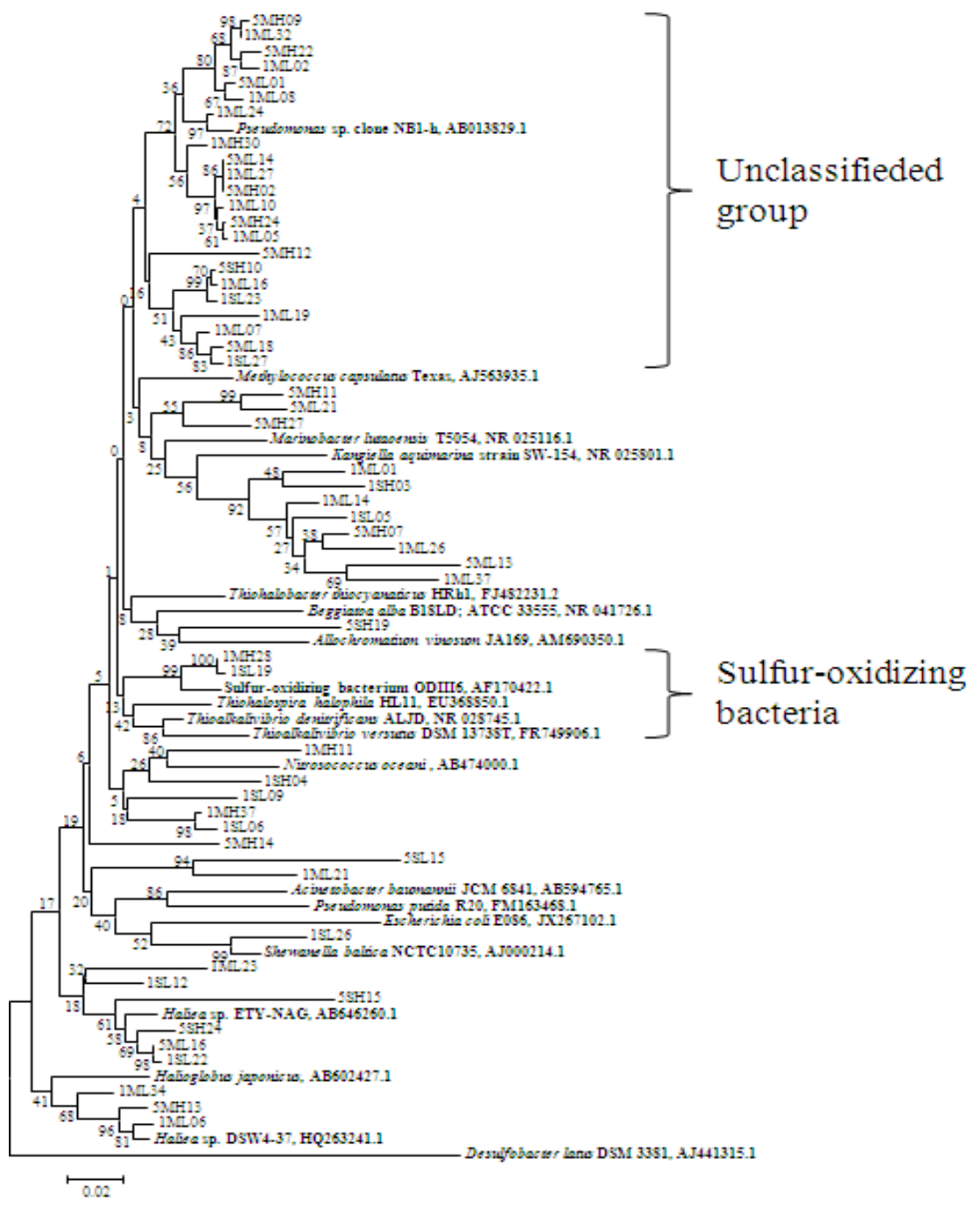

Figure 4. Neighbor-joining tree of Gammaproteobacteria clones based on partial 16S rRNA gene sequences 


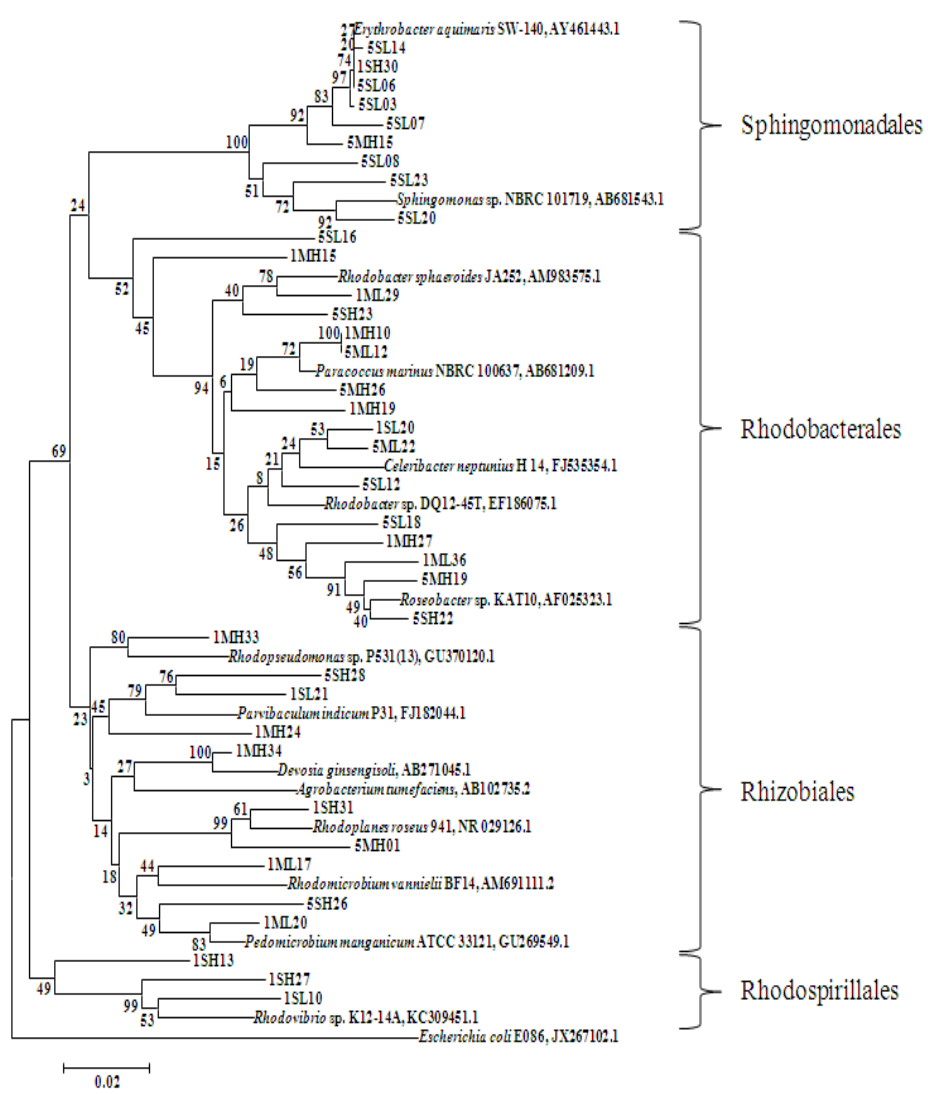

Figure 5. Neighbor-joining tree of Alphaproteobacteria clones based on partial 16S rRNA gene sequences

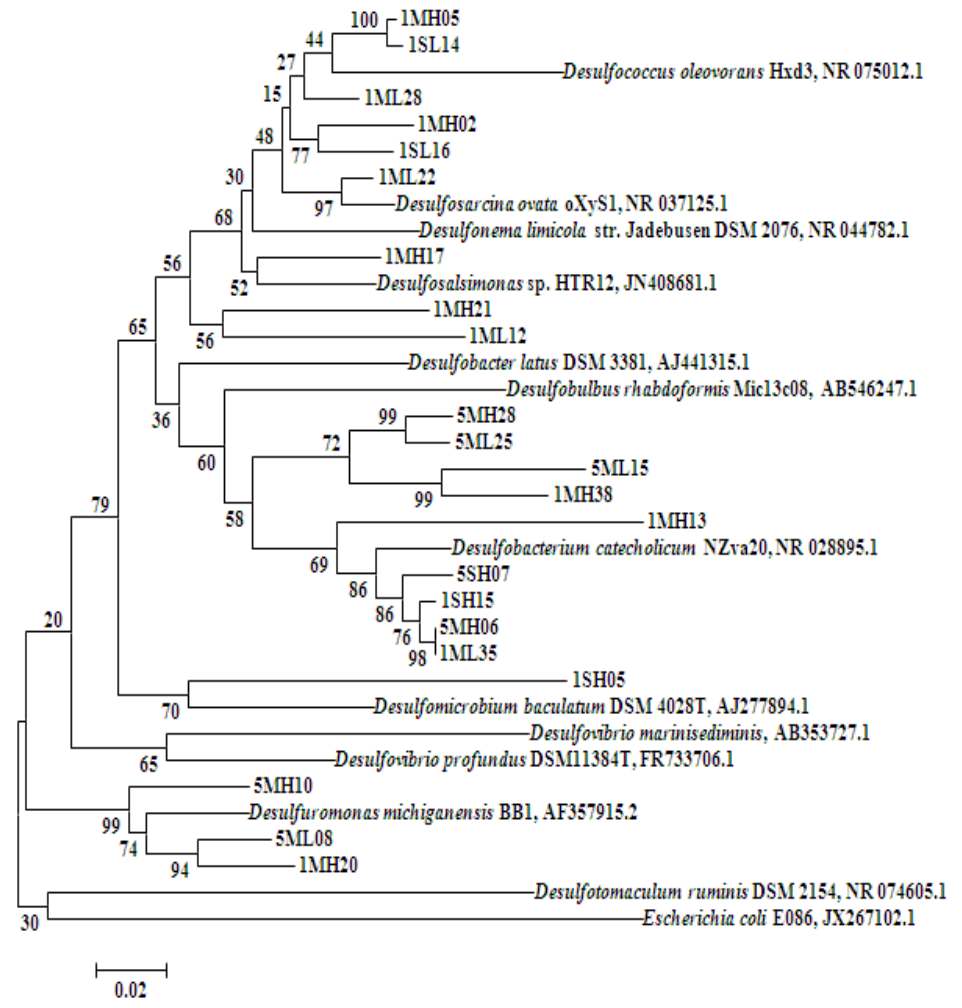

Figure 6. Neighbor-joining tree of Deltaproteobacteria clones based on partial 16S rRNA gene sequences 
(Liem et al.)

The SRB communities in the Midorikawa and Shirakawa estuaries were quite diverse. However, SRB were detected mainly in the Midorikawa estuary and were observed to a greater extent in January and at the high tide position. About $10 \%$ of the analyzed clones were SRB (Fig. 3), but few SOB clones were detected (Fig. 4), even though in an environmentally conserved tidal flat the hydrogen sulfide generated by SRB would likely be oxidized by SOB.

Anaerobic, facultatively anaerobic, and aerobic bacteria were observed in not just Proteobacteria, but also in the Chloroflexi group. However, in Actinobacteria and Bacteroidetes only aerobic bacteria were observed in both estuaries, both seasons, and both tidal positions (data not shown). Many of the identified clones were similar to salt-tolerant genera such as Ilumatobacter [22] and Aestuariicola [23]. The results presented here suggest that not only aerobic SOB, but also anaerobic phototrophic purple bacteria and anaerobic SRB might coexist in the top $5 \mathrm{~cm}$ of the sediments in the Shirakawa and Midorikawa.

At those conserved tidal flats, the ratio of Gammaproteobacteria and Alphaproteobacteria were higher than that of Deltaproteobacteria, the hydrogen sulfide producer. In comparison, at another location in Japan which is functionalized for intensive shellfish aquaculture, Deltaproteobacteria were detected as the most abundant [24]. Abundance of Deltaproteobacteria is stimulated by high content of organic matter and thus leads to enhancement of hydrogen sulfide production by the bacteria.

\section{CONCLUSION}

According to $16 \mathrm{~S}$ rRNA, the bacterial community was found in high diversity with many clones close to uncultured strains in the tidal flats. Complex material cycles involving aerobic and anaerobic activities may mostly exist in the surface layer of sediment which was mainly performed by the abundant Gammaproteobacteria. The dominance of Gammaproteobacteria over anaerobic Deltaproteobacteria can be an indicator for unspoilled tidal flats.

\section{REFERENCES}

[1] Sorokin, D.Y., T.P. Tourova, E.Y. Bezsoudnova, A. Pol, G. Muyzer. 2007. Denitrification in a binary culture and thiocyanate metabolism in Thiohalophilus thiocyanoxidans gen. nov. sp. nov. - a moderately halophilic chemolithoautotrophic sulfur-oxidizing Gammaproteobacterium from hypersaline lakes. Arch. Microbiol. 187. 441-450.

[2] Andrade, L.L., D.C. Leite, E.M. Ferreira, L.Q. Ferreira, G.R. Paula, M.J. Maguire, C.R. Hubert, R.S. Peixoto, R.M. Domingues, A.S. Rosado. 2012. Microbial diversity and anaerobic hydrocarbon degradation potential in an oil-contaminated mangrove sediment. Microbiol. 12. 186-195.

[3] Alejandro, A.G., R.M. Ramon, M. Silvia. 2013. Characterization of the anaerobic microbial community in oil-polluted subtidal sediments: aromatic biodegradation potential after the Prestige oil spill. Environ. Microbiol. 15. 77-92.

[4] Jin, H.M., J.M. Kim, H.J. Lee, E.L. Madsen, C.O. Jeon. 2012. Alteromonas as a key agent of polycyclic aromatic hydrocarbon biodegradation in crude oil-contaminated coastal sediment. Environ. Sci. Technol. 46. 7731-7740.

[5] Gillan, D.C., B. Danis, P. Pernet, G. Joly, P. Dubois. 2005. Structure of sedimentassociated microbial communities along a heavy-metal contamination gradient in the marine environment. Appl. Environ. Microbiol. 71. 679-690.

[6] Sun, M.Y., K.A. Dafforn, M.V. Brown, E.L. Johnston. 2012. Bacterial communities are sensitive indicators of contaminant stress. Marine Poll. Bull. 64. 1029-1038.

[7] Tanaka, S., Y. Tashiro, N. Mitsutake, Y. Nakazono, G. Kobayashi, T. Kato, K. Kanda. 2011. Analysis of bacterial community structures in coastal sediments in Ariake sea. Seibutsukogaku. 89. 161-169.

[8] Kim, B.K., Y.D. Park, H.M. Oh, J. Chun. 2009. Identification and characterization of metagenomic fragments from tidal flat sediment. J. Microbiol. 47. 402-410.

[9] Mount, D.W. 2007. Using the Basic Local Alignment Search Tool (BLAST). Cold Spring Harb Protoc.

[10] Thompson, J.D., T.J. Gibson, F. Plewniak, F. Jeanmougin, D.G. Higgins. 1997. The ClustalX windows interface: flexible strategies for multiple sequence alignment aided by quality analysis tools. Nucleic Acids Res. 24. 4876-4882.

[11] Tamura, K., J. Dudley, M. Nei, S. Kumar. 2007. MEGA4: Molecular Evolutionary Genetics Analysis (MEGA) software version 4.0. Mol. Biol. Evol. 24. 1596-1599. 
[12] Japanese Industrial Standards Committee: Organic matter. In: Namiki, H. (Ed). Testing methods for industrial wastewater, JIS K 0102. Japanese Standards Association.

[13] Yanagibayashi, M., Y. Nogi, L. Li, C. Kato. 1999. Changes in the microbial community in Japan Trench sediment from a depth of $6292 \mathrm{~m}$ during cultivation without decompression. FEMS Microbiol. Lett. 170. 271-279.

[14] Yoon, J.H., T.K. Oh, Y.H. Park. 2004. Kangiella koreensis gen. nov., sp. nov. and Kangiella aquimarina sp. nov., isolated from a tidal flat of the Yellow Sea in Korea. Int. J. Sys. Evol. Microbiol. 54. 1829-1835.

[15] Romanenko, L.A., N. Tanaka, G.M. Frolova, V.V. Mikhailov. 2010. Kangiella japonica sp. nov., isolated from a marine environment. Int. J. Sys. Evol. Microbiol. 60. 2583-2586.

[16] Hozuki, T., T. Ohtsuka, K. Arai, K. Yoshimatsu, S. Tanaka, T. Fujiwara, 2010. Effect of salinity on hydroxylamine oxidation in a marine ammonia-oxidizing gammaproteobacterium, Nitrosococcus oceani strain NS58: Molecular and catalytic properties of tetraheme cytochrome $c-554$. Microbes Environ. 25. 95-102.

[17] Laurent, U., I. Laurent, L. Franc, L. Philippe. 2009. Haliea rubra sp. nov., a member of the Gammaproteobacteria from the Mediterranean Sea. Int. J. Sys. Evol. Microbiol. 59. 1188-1192,.

[18] Suzuki, T., Nakamura, T., and Fuse, H. 2012. Isolation of two novel marine ethyleneassimilating bacteria, Haliea species ETY-M and ETY-NAG, containing particulate methane monooxygenase-like genes, Microbes Environ. 27. 54-60.

[19] Sorokin, D.Y., T.P. Tourova, G. Muyzer, G.J. Kuenen. 2008. Thiohalospira halophila gen. nov., sp. nov. and Thiohalospira alkaliphila sp. nov., novel obligately chemolithoautotrophic, halophilic, sulfur-oxidizing gammaproteobacteria fromy hypersaline habitats. Int. J. Sys. Evol. Microbiol. 58. 1685-1692.

[20] Daly,K., R.J. Sharp, A.J. McCarthy. 2000. Development of oligonucleotide probes and PCR primers for detecting phylogenetic subgroups of sulfate-reducing bacteria. Microbiol. 146. 1693-1705.

[21] Suzuki, D., A. Ueki, A. Amaishi, K. Ueki. 2007. Diversity of substrate utilization and growth characteristics of sulfate-reducing bacteria isolated from estuarine sediment in
Japan. J. Gen. Appl. Microbiol. 53. 119-132.

[22] Matsumoto, A., H. Kasai, Y. Matsuo, S. Omura, Y. Shizuri, Y. Takahashi. 2009. llumatobacter fluminis gen. nov., sp. nov., a novel actinobacterium isolated from the sediment of an estuary. J. Gen. Appl. Microbiol. 55. 201-205.

[23] Yoon, J.H., S.J. Kang, Y.T. Jung, T.K. Oh. 2008. Aestuariicola saemankumensis gen. nov., sp. nov., a member of the family Flavobacteriaceae, isolated from tidal flat sediment. Int. J. Sys. Evol. Microbiol. 58. 2126-2131.

[24] Asami, H., M. Aida, K. Watanabe. 2005. Accelerated Sulfur Cycle in Coastal Marine Sediment beneath Areas of Intensive Shellfish Aquaculture. Appl. Env. Microbiol. 71. 29252933. 